\title{
CONSOLIDACIÓN DEMOCRÁTICA Y PODER JUdiCIAL: LOS RIESGOS DE LA JUDICIALIZACIÓN DE LA POLÍTICA
}

\author{
JAVIer COUSO \\ Universidad Diego Portales, Chile
}

\begin{abstract}
Resumen
De un tiempo a esta parte, se ha instalado en el léxico de la ciencia política la expresión “judicialización de la política", para referirse a la creciente importancia de las cortes en el campo político. En este artículo, se aborda el rol de ésta en las democracias emergentes, para indagar si las esperanzas puestas en ella para apoyar procesos de consolidación democrática están bien fundadas. Luego de describir la articulación del discurso experto que erigió al activismo judicial como un elemento decisivo del Estado democrático de derecho, y después de analizar las condiciones de posibilidad y los peligros de la judicialización en las nuevas democracias, se arguye que una prematura introducción de esta última pone en peligro la independencia del poder judicial.

Abstract

Over the last decade or so, the notion of the "judicialization of politics" has become part and parcel of the language of political science. The term refers to the increased relevance of the courts in the political domain. In this article, the author assesses the role of judicialization in support of processes of democratic consolidation, in order to evaluate if the hopes placed on it are well founded. After describing the articulation of the expert discourse which enacted judicial activism as a core element of the rcombatir ule of law, and after analysing the preconditions and risks of it in new democracies, the article argues that the premature introduction of judicialization represents a threat to the independence of the judiciary.
\end{abstract}

PALABRAS CLAVE • Judicialización • Cortes • Democracia • Consolidación • Constitucionalidad

\section{LA JUDICIALIZACIÓN DE LA POLITICA EN LAS DEMOCRACIAS EMERGENTES}

De un tiempo a esta parte, se ha instalado en el léxico de la ciencia política la expresión "judicialización de la política". Mediante esta noción algo equívoca se alude a la creciente importancia que han adquirido las cortes de justicia en el campo político. A causa de ello, conflictos que antaño eran resorte de las ramas ejecutiva y legislativa del Estado -0 de partidos políticos, sindicatos y otras instancias-, son ahora resueltos "en sede judicial", por tribunales de todo tipo, que utilizan el lenguaje de los derechos (Glendon, 1991). Por otra parte, el concepto se utiliza también para describir la creciente asertividad de las cortes de justicia frente a casos de corrupción política, en que jueces y fiscales persiguen sin miramientos incluso a las más encumbradas figuras políticas, como ocurrió en el paradigmático caso de Italia hacia comienzos de los años 90, que eventual- 
mente derivó en una crisis de proporciones y en un remozamiento completo de su sistema político (Volcansek, 2000, 1994; Guarnieri, 1992).

Aun cuando desde una perspectiva amplia se puede conceptualizar como "política" cualquier decisión con impacto público emanada de las cortes de justicia, el hecho es que hasta hace poco éstos no eran considerados como una arena propiamente política, con la excepción de Estados Unidos (Dahl, 1957; Shapiro, 1962, 1964). De ahí que la noción de judicialización política surja tan sólo en la última década. Sea como fuere, y atendido el impacto político que ha adquirido la judicatura, se ha vuelto indispensable incorporar la variable judicial en cualquier intento de análisis más o menos sistemático de la evolución política de un país determinado.

El interés en este nuevo ámbito de la política ha sido especialmente marcado en la literatura sobre transición y consolidación democráticas (Chavez, 2004; Koopmans, 2003; Schwartz, 2000; Solyom \& Brunner, 2000; Boyle \& Sherif, 1997; Stotzky, 1994), que en los últimos años ha enfatizado el rol que pueden cumplir las cortes en limitar el poder de los gobiernos en beneficio de los derechos individuales, ampliamente considerados como importantes factores en la consolidación y profundización democráticas.

La judicialización de la política es un fenómeno multifacético y que reviste distintas significaciones, dependiendo de la modalidad de la cual se trate, así como del contexto en el que se desarrolla. De hecho, difiere sustancialmente dependiendo de sí se produce a propósito de cortes constitucionales que se involucran en el diseño e implementación de políticas públicas (como en Estados Unidos), o a propósito de casos de persecución de la corrupción política (como en Italia). Asimismo, la dinámica de la judicialización varía significativamente dependiendo de sí se da en el contexto de democracias consolidadas o en democracias emergentes.

En este trabajo se aborda la judicialización de la política en países embarcados en procesos de consolidación democrática, específicamente respecto del rol de las cortes en el control de la supremacía constitucional. El interés por este aspecto del fenómeno surge del hecho de que, junto con el retorno o la introducción de regímenes democráticos en decenas de países de América Latina, Europa oriental y Asia, la gran mayoría de estas nuevas democracias simultáneamente inauguraron sendos mecanismos de control judicial de la Constitución, convencidos de que ello contribuiría a someter a las autoridades políticas al imperio del derecho (Ginsburg, 2003). Aun cuando las modalidades y mecanismos de revisión judicial de la Constitución difieren entre dichos países, la noción básica de imponer controles jurídicos al poder político en defensa de los derechos humanos, es suscrita por la vasta mayoría de las democracias emergentes ${ }^{1}$. Ante esto, surge la pregunta de si las esperanzas puestas en este tipo de mecanismos para apoyar procesos de consolidación democrática están bien fundadas. El presente artículo pretende comenzar a responder esta cuestión.

La estructura del artículo es la siguiente. En primer término, se describe la articulación del discurso experto que erigió el activismo judicial en materia de control de la supremacía constitucional como un elemento decisivo en la consolidación de las democracias emergentes. Luego, se proveen herramientas conceptuales para identificar con precisión los contextos en que -más allá de la existencia nominal de instituciones de control constitucional- se está efectivamente en presen-

Por cierto, el que los regímenes autoritarios que las antecedieron hubieran incurrido en brutales violaciones de los derechos de las personas, sin duda contribuyó a la introducción del control judicial de la constitucionalidad de las leyes. 
cia de instancias de judicialización de la política, así como las pre condiciones hasta ahora identificadas por la literatura especializada para que ésta ocurra. Finalmente, el artículo termina con una nota de cautela acerca de las esperanzas puestas en esta variante de judicialización de la política en las democracias emergentes, arguyendo que un activo control de la constitucionalidad de las leyes puede acabar destruyendo la independencia del poder judicial, elemento sine qua non del Estado democrático de derecho.

\section{LOS PROBLEMAS DEL MINIMALISMO DEMOCRÁTICO}

A comienzos de la década de los noventa, la democracia como sistema político parecía haber llegado a su cenit, ya que por esos años culminaba lo que se conoció como la "tercera ola de la democracia" ${ }^{2}$ llamada así porque docenas de países establecieron democracias electorales en esa época. Como resultado de este proceso, por primera vez en la historia de la humanidad hubo más personas viviendo bajo regímenes democráticos que sujetos al autoritarismo ${ }^{3}$. A pesar del gran entusiasmo inicial creado por esta ola democratizadora, al poco tiempo, estudiosos de los procesos de transición y consolidación democrática comenzaron a cuestionar el estatus de tal de muchos de los países de la "tercera ola", argumentando que más allá del rótulo de democráticos, muchos de ellos eran en verdad autoritarismos disfrazados.

El surgimiento de este tipo de regímenes puso al concepto de democracia en el centro de la discusión. Esta preocupación, que había desempeñado un rol importante en la ciencia política inmediatamente después de la segunda guerra mundial, se constituía así nuevamente en un ítem importante de la agenda de la disciplina, que durante décadas había aceptado la noción schumpeteriana de democracia ${ }^{4}$, que enfatiza la libertad electoral y la competencia entre distintas opciones políticas como sus elementos constitutivos.

El consenso conceptual que esta versión minimalista de democracia aglutinó comenzó, sin embargo, a romperse en los años noventa, cuando importantes figuras de los estudios democráticos cuestionaron su utilidad en vista de la baja calidad democrática de muchos países que, de acuerdo con la concepción minimalista, debían ser consideradas como tales. En efecto, aun cuando se concedía que en tales naciones las autoridades políticas eran elegidas mediante elecciones libres y competitivas, existía gran insatisfacción por el carácter autoritario de estos gobiernos una vez

2 Esta noción fue introducida por el cientista político Samuel Huntington (1996, p. 3), para referirse al proceso de diseminación de regímenes políticos democráticos entre 1974 y 1990. Durante esos años, más de 30 países iniciaron procesos de transición a la democracia, doblando el número de sistemas de tal índole que existían hasta ese momento. De acuerdo con Huntington, la primera "larga ola" democrática habría comenzado a comienzos del siglo XIX, con la expansión del sufragio en los Estados Unidos, extendiéndose hasta 1926, cuando el número de democracias alcanzó a 29. La "segunda ola democrática" habría partido inmediatamente después de la segunda guerra mundial, y hasta 1966, cuando se registraron un total de 36 sistemas democráticos en el mundo.

3 En efecto, hacia fines de la denominada "tercera ola de la democracia", Diamond y Platter (1993) informaban en 1996 que en ese momento existían 117 democracias en el mundo, que contaba entonces con 191 países independientes.

$4 \quad$ De acuerdo con Schumpeter (1942), p. 284.: "Democracia significa solamente que el pueblo tiene la oportunidad de aceptar o rechazar a los que los gobiernan" (la traducción de esta cita, así como de todas las del presente trabajo, son del autor). Este entendimiento electoralista del sistema democrático había sido el dominante durante la segunda mitad del siglo XX, puesto que permitió superar la polémica entre los demócratas "a secas" y aquellos que favorecían concepciones más densas de la democracia, como la democracia "liberal" o la democracia "popular".

5 Richard Holbrooke, citado por Fareed Zakaria (1997). 
elegidos. Como lo planteó con crudeza un autor: "Supongamos que se declara que la elección fue libre y justa, (y los elegidos) son racistas, fascistas, separatistas y se oponen públicamente a (la paz y la reintegración). Ese es el dilema"5.

La respuesta a la experiencia cada vez más frecuente de autoridades que -aunque llegadas al poder mediante procesos democráticos-, gobiernan luego con total olvido de las normas legales o constitucionales que supuestamente regulan el ejercicio del poder político, fue un profundo cuestionamiento a la concepción puramente electoralista de democracia. Como lo plantearon con agudeza Handelman y Tessler (1999:3), el problema no se limita a que en estas nuevas democracias los gobernantes abusen de su poder una vez elegidos, sino que su proceder también amenaza la viabilidad futura de la democracia electoral. En sus palabras: "(la) corrupción masiva y otras iniquidades en el sistema jurídico... todo esto socava la democracia electoral misma, amenazando la supervivencia (de estos regímenes)".

En este tipo de "democracias autoritarias", vastos segmentos de la población, generalmente los pobres, la población rural y los miembros de las minorías étnicas, son tratados por los gobiernos elegidos democráticamente en forma no muy diferente a la utilizada por los regímenes autoritarios del pasado (O'Donnell et al., 1999). Las similitudes incluyen violación de los derechos humanos por parte de la policía, falta de acceso al sistema judicial, y la existencia de un trato arbitrario por parte de funcionarios corruptos, particularmente vinculados al ejecutivo (Huntington, 1996:9)6.

La toma de conciencia acerca de la verdadera naturaleza de estos regímenes, llevó eventualmente a negarles el carácter de democráticos. Así, por ejemplo, Karl y Schmitter (1996:52) abandonaron la visión schumpeteriana de la democracia, acusándola de estar basada en lo que llamaron la "falacia del electoralismo", esto es, "(...) la creencia en que sólo por el hecho de llevar a cabo elecciones, la acción política se encaminará a justas pacíficas entre elites y entregará legitimidad pública a los ganadores (...)".

El rechazo de una concepción que durante décadas dominó la ciencia política, fue luego suscrito por dos figuras señeras de los estudios sobre transición y consolidación democráticas, Linz y Stepan (1996:15), quienes afirmaron:

(...) ningún régimen debería ser llamado democracia, a menos que sus dirigentes gobiernen en forma democrática. Si los funcionarios del poder ejecutivo, elegidos libremente (sin que se tome en cuenta la magnitud de su mayoría) infringen la Constitución, violan los derechos de los individuos y de las minorías, se entrometen en las funciones legítimas de la legislatura, y así fallan en gobernar dentro de los límites del estado de derecho, sus regímenes no son democráticos.

Las objeciones al modelo minimalista recién descritas terminaron por persuadir a la vasta mayoría de quienes trabajan en este campo acerca de los defectos de la concepción minimalista, llevándolos a intentar reformular la idea de democracia, de modo de poder criticar estos regímenes desde la propia teoría democrática. Abandonar la tradición no es, sin embargo, nada fácil, ya que la falta

$6 \quad$ En palabras de Samuel Huntington (1996, p. 9): "Una amenaza seria contra la democracia es el abuso de poder de la rama ejecutiva, que ocurre cuando un mandatario elegido concentra el poder en sus manos, subordinando o incluso clausurando al poder legislativo, y gobernando por decreto. Esto ocurre en cierta medida en Rusia, en Bielorrusia y otros países del ámbito ex comunista. También es común en América Latina, donde existen varias de estas democracias autoritarias". Un ejemplo de esto último fue Perú bajo la administración de Fujimori, cuando se decretó unilateralmente el cierre del Congreso (en 1992). 
de otra conceptualización precisa que reemplace la anterior podría privar a los estudios de democratización de una herramienta analítica crucial. Además, está siempre presente el riesgo de que un entendimiento más denso de esta categoría fundamental sea tan demandante que sólo un puñado de naciones pueda aspirar a ser calificado de democrático.

El primer intento por refinar el concepto de democracia introdujo la noción de "consolidación", permitiendo argumentar que los regímenes que exhiben graves faltas de respeto a los valores constitucional-liberales después de haber llegado al poder mediante elecciones universales, son "democracias no consolidadas". Desde la perspectiva de este modelo, la carencia de un respeto irrestricto de los derechos individuales después del momento electoral evidenciaría que dichos regímenes aún no alcanzan suficientes grados de consolidación. Aunque persuasiva, esta estrategia no fue del todo exitosa (aunque la nomenclatura que acuñó tiene un uso extendido), ya que a poco andar se planteó la inquietud acerca de qué se debía entender, exactamente, por "consolidación". Otra complicación es el carácter teleológico implícito en la expresión, que sugiere que todos los países en transición a la democracia están dirigidos inevitablemente a una eventual "consolidación" como destino final".

Mientras quienes apostaban a la idea de consolidación perfeccionaban esta aproximación conceptual, otros propusieron otra estrategia, consistente en caracterizar estos nuevos regímenes en forma más analítica, realizando una descripción detallada de la forma como funcionan. Uno de ellos, Guillermo O'Donnell (1998:164), hizo una importante contribución al problema, al introducir el concepto de "democracia delegativa" para referirse a los sistemas cesaristas en que líderes elegidos democráticamente se comportan después de manera abusiva. En las palabras de este autor:

Las democracias delegativas descansan en la premisa de que quien sea el que gane las elecciones a la presidencia, de ahí en adelante está autorizado para gobernar como él o ella juzguen conveniente, restringido solamente por los hechos duros de la existencia de relaciones de poder, y por el término de su mandato limitado constitucionalmente.

Más allá de los esfuerzos por superar las versiones minimalistas de democracia recién anotados, el hecho es que todavía persisten defensores de una aproximación puramente electoral a la misma ${ }^{8}$. Las consecuencias de estas divergencias no son menores, ya que dependiendo de qué tan estricta sea la definición de democracia que se adopte el número de regímenes que tendrán el status de tal variará significativamente. Así por ejemplo, en 1995 se daba la peculiar situación de que mientras que algunos estudiosos contaban en 117 las democracias del mundo, otros sólo contabilizaban 76 .

Una discusión a fondo de la definición más apropiada de democracia escapa al alcance de este trabajo. Sin embargo, vale la pena señalar que el escrutinio acabado de las condiciones estipula-

$7 \quad$ Schmitter (1993, p. 76-77) objeta precisamente esta noción: "El deseo ampliamente extendido 33de las inexpertas neo democracias de imitar las normas básicas y las instituciones de las democracias liberales establecidas no es, de ninguna manera, una garantía de éxito. No hay ninguna prueba de que la democracia sea inevitable, irrevocable o una necesidad histórica. No llena ningún requisito funcional indispensable del capitalismo, ni responde a ningún imperativo ético dentro de la evolución social. Hay muchas razones para creer que su consolidación exige un esfuerzo extraordinario y continuo —el que muchos países no son capaces de hacer".

8 La persistencia del modelo electoralista de la democracia es patente en un reciente artículo sobre democratización de Rogoswky (1998, p. 48), quien afirma: "Siguiendo una práctica académica casi universal (...) defino democracia como la asignación regular del poder político mediante el voto igualitario y efectivo de la totalidad de la población adulta de un Estado determinado ....".

9 Véase Diamond (1999, p. 1 y 7$).$ 
das por la noción de poliarquía revela que éste incluye importantes derechos liberales-constitucionales. Tomemos, por ejemplo, la libertad de asociación y de expresión, dos derechos reconocidos como condiciones sine qua non del gobierno democrático. Aunque de acuerdo con este enfoque dichas libertades sólo serían imprescindibles en los procesos eleccionarios, es difícil imaginar que los gobernantes tengan incentivos para respetar la libertad de expresión o el derecho de asociación de las fuerzas de oposición en época de elecciones, si no están limitados por una Constitución liberal que establezca la separación de los poderes del Estado, la independencia del poder judicial y el respeto al principio de legalidad, en otras palabras, sin un Estado de derecho en forma ${ }^{10}$. La posibilidad de que las referidas libertades electorales "caigan del cielo", por así decirlo, precisamente en el crucial momento de las elecciones, parece ingenua.

\section{DEMOCRACIA Y LIBERALISMO}

Aceptada la necesidad de sustituir definiciones minimalistas de "democracia" por otras más robustas, la disciplina se dedicó a analizar las características esenciales de los casos paradigmáticos de democracias bien establecidas, como las de Europa occidental y las ex colonias anglosajonas. El análisis de estos países llevó eventualmente a identificar elementos que habían sido poco estudiados por la literatura sobre transición democrática hasta entonces.

El primer elemento común a las democracias consolidadas que llamó la atención fue las presencia de instituciones liberales. En efecto, todas las democracias consolidadas exhiben un sólido Estado de derecho, separación de poderes, una rama judicial independiente y respeto por los derechos humanos básicos de sus ciudadanos. Estos elementos están en verdad tan imbricados con estos regímenes, que muchos creen que la idea de una 'democracia no liberal' constituye un contrasentido (Nino, 1986).

Lo dicho hace necesario especificar en qué consiste el liberalismo político. Uno de los autores más prolíficos del campo de estudios sobre democratización, Larry Diamond (1999:10-11), resume los principales elementos del liberalismo de la siguiente manera:

Además de los componentes de la democracia electoral, (la democracia liberal) requiere, primero, la ausencia de dominios de poder reservados para los militares u otros actores que no dan cuenta de sus actos ante el electorado, ya sea en forma directa o indirecta. Segundo, además de la responsabilidad vertical de los gobernantes para con sus gobernados (asegurada principalmente a través de las elecciones), se hace necesaria la responsabilidad horizontal recíproca de los funcionarios que están en el poder; esto limita al poder ejecutivo y así protege el constitucionalismo, la legalidad, y el proceso deliberativo. En tercer lugar, es necesario que haya resguardos que protejan un pluralismo político y cívico. También, que haya libertades tanto para los individuos como para los grupos, de tal modo que los intereses encontrados y sus valores puedan ser expresados y puedan competir a través de procesos continuos de articulación y representación, que vayan más allá de las elecciones periódicas. proviene del deseo de proteger el sistema democrático, como sea que se entienda. El derecho a la libertad de expresión y el derecho a sufragar son ejemplos (...) del hecho que las mayorías no pueden conculcar estos derechos si se quiere preservar la democracia". 
Como se advierte de esta apretada síntesis del ideario liberal, a fin de cuentas el elemento crucial de esta doctrina es el individuo. En efecto, la noción de que el individuo es la unidad básica de análisis, en lugar del "pueblo", la "comunidad" o la "nación", constituye uno de los pilares del liberalismo. Este énfasis en el individuo encuentra expresión institucional en el conjunto de prohibiciones que el Estado liberal impone a las autoridades políticas en resguardo de los derechos de las personas.

Esto último había sido suficientemente resaltado hace ya dos siglos por Benjamin Constant (1988:309), quien hizo el feliz distingo entre "la libertad de los antiguos" y la "libertad de los modernos". De acuerdo con Constant, mientras que la primera se preocupaba fundamentalmente por el derecho de los ciudadanos a participar en el auto gobierno de la comunidad, la segunda dice relación con los derechos y las libertades individuales, especialmente respecto de la amenaza que representa el poder político. Por otra parte -y como lo ha subrayado Gray (1986)-, en la era contemporánea la clave de la libertad individual descansa en el imperio de la ley, que asegura que tanto los ciudadanos como las autoridades políticas estén sujetos al imperio del derecho.

Otro elemento que diferencia a la democracia meramente electoral de la liberal es la presencia de lo que O'Donnell (1998:185) llama "instituciones de responsabilidad horizontal" (institutions of horizonal accountability), esto es, mecanismos de contención de los abusos de las autoridades elegidas por el pueblo durante sus mandatos. En sus palabras:

La poliarquía, aunque no esté formalmente institucionalizada, marca una inmensa mejoría respecto de regímenes autoritarios de todo tipo. Lo que falta, sin embargo, es otra dimensión de la obligación de rendir cuentas, que llamo 'horizontal'. Con esto quiero decir los controles que las agencias del Estado se supone que ejercen unas sobre otras. Todas las poliarquías institucionalizadas incluyen varias agencias dotadas de autoridad legalmente definida para sancionar acciones ya sea ilegales o de alguna manera inapropiadas cometidas por otros agentes. Esta es una expresión del Estado de derecho en una de las áreas donde es más difícil de implantar, vale decir, sobre los agentes del Estado, especialmente funcionarios de alto rango. La idea básica es que las instituciones formales tienen límites bien definidos y legalmente establecidos que delimitan el ejercicio adecuado de su autoridad, y que hay agencias del estado que tienen poder para controlar y corregir los quiebres de esos límites, cometidos por cualquier funcionario 0 agencia (...) A diferencia de esto, en la mayoría de las nuevas poliarquías existe muy poca obligación de responder (por violaciones del Estado de derecho).

La aproximación de O'Donnell sobre el papel que deben desempeñar las instituciones de "responsabilidad horizontal" ha recibido una amplia acogida en los estudios de democratización. Su terminología, sin embargo, puede ser sustituida por otras más clásicas, como "Estado de derecho" o "constitucionalismo". De hecho, el propio O'Donnell (1999) reconoció poco después que los valores envueltos en la obligación impuesta a las autoridades para que rindan cuentas de sus actos a otros órganos del Estado durante el período que transcurre entre elecciones, son similares a los contenidos en el tradicional concepto de "Estado de derecho" (rule of law), que enfatiza la seguridad del individuo y de las minorías frente a los abusos de la mayoría. 


\section{DEL ESTADO DE DERECHO A LA JUDICIALIZACIÓN DE LA POLITICA}

El que la democracia pueda consolidarse mediante la implementación efectiva de un Estado de derecho no es algo novedoso, y hay mucho que decir en su favor. Lo que sí constituye una novedad es la idea de que el control judicial de la constitucionalidad de la ley es consustancial al Estado de derecho, y por tanto importante para los procesos de consolidación. Este paso teórico ha dado lugar a una demanda global que Klug (1997) llama "constituciones justiciables", expresión de la esperanza puesta por muchos en el rol que las cortes puedan desempeñar en la consolidación democrática ${ }^{11}$.

De acuerdo con esta concepción, dado que el objetivo final del Estado de derecho es obligar al gobierno a respetar las reglas básicas del juego consagradas en la Constitución, es indispensable introducir un cuerpo independiente, las cortes de justicia, dotado de la facultad de controlar el respeto efectivo de la Constitución por parte del resto de las autoridades políticas, incluidos los poderes ejecutivo y legislativo ${ }^{12}$. Un ejemplo de la vinculación que se hace entre procesos de consolidación democrática y la introducción de mecanismos de control judicial de la constitucionalidad de las leyes, se encuentra en Hilbink (1999:501), autora de un reciente estudio sobre la judicatura chilena, quien ha defendido la necesidad de un poder judicial comprometido con la promoción activa de los valores liberales, mediante el uso de sus poderes de control judicial de la Constitución. En sus palabras:

En países en transición a la democracia que vienen de períodos de extrema brutalidad impulsada por el Estado por el disenso social o la guerra, las cortes pueden dar un importante ejemplo de moralidad (liberal) y de ciudadanía democrática.

Esta cita refleja una tendencia que ha adquirido gran fuerza entre politólogos interesados en la consolidación democrática de los países de la "tercera ola": la apuesta a que jueces liberales instilen valores compatibles con el Estado constitucional de derecho en aquellas nuevas democracias en donde la clase política en su conjunto tiende a comportarse de manera no liberal (Gloppen et al, 2003; Smith, 2003). La idea es que jueces ilustrados y abiertos a la deliberación racional contengan los impulsos autoritarios de los políticos profesionales que pueblan los demás poderes del Estado ${ }^{13}$.

Otro autor que defiende esta posición es Holland (1991, p. 3), quien argumenta que "el activismo judicial generalmente se encuentra al servicio del liberalismo y los derechos individuales", aunque también reconoce que, en ocasiones, puede ponerse al servicio de regímenes no liberales, mencionando el caso de Egipto (el caso iraní también ilustra este punto). La defensa del control judicial de la constitucionalidad de las leyes tiene una larga historia. El primero en argumentar a favor de ella fue Alexander Hamilton, en "El Federalista" № 78 (1945). En Europa, Sieyés también defendió esta institución. La idea central de estos juristas era que el control judicial de la Constitución haría del principio de supremacía constitucional algo concreto, asegurando que la Constitución, como ley suprema, tuviera una primacía efectiva respecto de la legislación aprobada por la legislatura. Algunos años más tarde, Tocqueville (1990, vol. 1, p. 107), comentaría aprobatoriamente la que era entonces una institución peculiar de los Estados Unidos: “...el poder investido en los tribunales de justicia norteamericanos para declarar una ley inconstitucional constituye una de las barreras más formidables que se han instituido jamás en contra de la tiranía de las asambleas políticas".

13 Esta conceptualización de la labor de los jueces constitucionales le debe mucho a la experiencia norteamericana con la revisión judicial de la Constitución desde la perspectiva algo idealizada que John Hart Ely (1980) y Ronald Dworkin $(1977,1986)$ tienen de la denominada "Corte Warren", conocida por sus decisiones favorables a personas que sufrieron discrimniación racial y falta de debido proceso. De acuerdo con esta noción acerca de la manera como los jueces actúan, ellos serían el paradigma de la deliberación pública desinteresada. 
En términos institucionales, esta apuesta se expresa en la defensa de un activo control judicial de la constitucionalidad de las leyes. Sintetizando el argumento: dado que la consolidación democrática depende de la existencia previa de un Estado constitucional de derecho, y atendido a que este último sólo sería posible con órganos judiciales que controlen la constitucionalidad de las leyes, ésta sería una condición necesaria para la consolidación. El problema de este modelo es que parte de una premisa empíricamente falsa, puesto que no es efectivo que sin control de la constitucionalidad de las leyes no se pueda establecer un Estado constitucional de derecho. De hecho, ni el récord histórico ni la teoría política contemporánea ofrecen una base sólida para sostener que sin ese tipo de controles es imposible consolidar un sistema democrático ${ }^{14}$. Ésta, por lo menos, ha sido la experiencia que nos muestra el régimen constitucional más antiguo del mundo, el Reino Unido, así como el caso de los Países Bajos, Suecia, Nueva Zelanda y Canadá (hasta 1982), todos los cuales lograron consolidar sus democracias sin contar con mecanismos de control judicial de la constitucionalidad de la ley.

\section{JUDICIALIZACIÓN NOMINAL Y EFECTIVA: LAS PRECONDICIONES DEL ACTIVISMO CONSTITUCIONAL}

En el supuesto de que -contra lo que se ha dicho recién- la "judicialización de la política" en la modalidad de control constitucional sea indispensable para consolidar procesos democráticos, parece importante determinar la posibilidades concretas de que se logre introducir este tipo de judicialización en las democracias emergentes, así como dimensionar el impacto democratizador que aquél tendría. En esta sección se pasará primero revista a los métodos existentes disponibles para determinar cúando se está en presencia de una corte constitucional que ha judicializado la política, para luego abordar las condiciones que favorecen la emergencia de este tipo de judicialización.

Con relación al primer punto planteado, es importante subrayar que aun cuando la mayor parte de los Estados constitucionales han conferido a la judicatura regular 0 a tribunales constitucionales especiales el control de la constitucionalidad de las leyes, el número de países con un sistema efectivo de control judicial de la constitución es significativamente menor. En palabras de Holland (1991:2):

El activismo judicial es un fenómeno distintivo del control judicial (de la Constitución). De hecho, aunque el control judicial se encuentra expresamente reconocido en las leyes de Suecia (...), la Corte Suprema de Suecia jamás ha encontrado que una ley del Riksdag contravenga la constitución.

En efecto, dado que existen muchos países en los cuales el control judicial de la Constitución es una cuestión meramente retórica, se hace necesario construir indicadores que ayuden a distinguir entre ejercicios efectivos del control judicial de ella y otros puramente nominales ${ }^{15}$. Dicho esto, debe señalarse que ello no siempre es fácil, por las consideraciones que se hacen a continuación.

Para una excelente defensa de este punto de vista véanse Jeremy Waldron (1996) y Mark Tushnet (1999).

La coexistencia de países con un control judicial de la Constitución puramente nominal y de aquellos en que el mismo es en efecto ejercido, llevó a los especialistas en estudios judiciales comparados a intentar explicar los factores que subyacen a esta realidad divergente. Entre otros, Ios trabajos de Guarnieri y Pederzoli (1999); Epp (1998); Tate y Vallinder (1995), y Shapiro y Stone (1994) han aportado mucha información sobre esta cuestión. 
El primer obstáculo para determinar el grado de activismo constitucional proviene del hecho que las cortes son meramente reactivas a lo actuado por las ramas propiamente "políticas" del Estado, el Ejecutivo y el Legislativo. Luego, si éstas no son ambiciosas en su producción legislativa, el control judicial ejercido por las cortes será reducido ${ }^{16}$. El segundo obstáculo es la frecuente estrategia de cortes que están intentando consolidar su legitimidad en el largo plazo, consistente en adoptar temporalmente una actitud deferente hacia el poder politico después de un período activista, con el propósito de acumular una reserva de legitimidad suficiente que les permita más adelante volver a adoptar una conducta activista. Este tipo de acción estratégica hace muy difícil la tarea de determinar niveles de activismo judicial en el mediano y largo plazo, puesto que no es fácil establecer si un período de pasividad judicial es señal de una tendencia permanente, o simplemente algo aislado ${ }^{17}$. Otra dificultad para establecer el nivel de activismo judicial de un país determinado, es que ello requiere que el obsevador adopte un punto de vista interno, esto es, prestar atención al contenido de la doctrina legal y la jurisprudencia de que se trate, lo que es una tarea compleja, especialmente cuando se estudia la política judicial de un país distinto del propio. Esto es necesario porque si no se conoce cabalmente el derecho del cual se trata, será imposible determinar si las cortes protegieron o no la supremacía de la Constitución, ya que ello supone tener un juicio ponderado acerca de la sujeción efectiva a la Constitución por parte del legislador. En atención a lo anterior, todo análisis riguroso del grado de activismo judicial de un país determinado supone sólidos conocimientos acerca del grado en que las opiniones judiciales estudiadas "están emitidas conforme a derecho"18.

Para ilustrar este último punto, supongamos que se intenta determinar el activismo judicial de un país en función de la cantidad de leyes apoyadas por el gobierno que son luego declaradas inconstitucionales por las cortes de justicia. En este escenario, mientras más leyes sean anuladas por las cortes, más activistas se reputarán dichas cortes. El problema de esta aproximación, sin embargo, es que si no se conoce bien la doctrina y la jurisprudencia específica en cuestión, no se podrá distinguir entre casos en que un gobierno es en general respetuoso de la Constitución pero, pese a ello, cortes activistas anularán leyes constitucionales con las cuales están en desacuerdo por motivos políticos, de aquellos casos en que el activismo de las cortes es una respuesta a un gobierno poco respetuoso de la Constitución. Por esto, todo análisis de los niveles de activismo judicial requiere conocer cabalmente la doctrina constitucional del país respectivo.

A pesar de los obstáculos para medir el grado de activismo judicial recién señalados, ello no ha impedido que los especialistas evalúen el activismo y la consiguiente relevancia política de las distintas cortes del mundo. Como sucede también con otras disputas académicas al parecer imposibles de resolver, los que se dedican a esta actividad conocen el activismo cuando lo ven. Así, es frecuente que se afirme, por ejemplo, que las cortes constitucionales de Israel y Hungría son "muy activas" $^{\prime 19}$, o que el Consejo Constitucional Francés fue "deferente" hasta el año $1974^{20}$.

De acuerdo con lo señalado por Shapiro y Stone (1994, p. 407): "Si el gobierno no está empujando al parlamento a promulgar legislaciones complejas y rebuscadas, entonces los jueces constitucionales no se verán enfrentados con una legislación muy controversial. Y en tal situación no esperaríamos ver grandes niveles de innovaciones constitucionales o producción de leyes judiciales por parte de las cortes constitucionales".

El caso de la Corte Europea de Justicia es también un ejemplo de este tipo de estrategia (Weiler, 1994).

Véase Ranney (1996).

Para el caso de Hungría, véase Seitzer (1999). Para el caso i sraelí, véase Edelman (1995).

Sobre el Consejo Constitucional francés, véase Stone (1992). 
¿Sobre qué bases se hacen estos juicios? Presumiblemente, estas afirmaciones se derivan del juicio de investigadores que conocen en detalle el contexto legal y político en el cual operan dichas cortes, y que en consecuencia, pueden evaluar el rol desempeñado por ellas. El problema de este tipo de evaluación erudita es que a menudo quienes reportan sobre el grado de activismo judicial no explicitan los criterios que utilizaron en sus diagnósticos.

Dadas las dificultades que una evaluación acerca de los niveles relativos de activismo judicial presenta, la aproximación propuesta por Epp (1998:2) puede ser útil, ya que ha elaborado un interesante enfoque para identificar el activismo judicial. En un estudio comparado sobre los factores que contribuyen al activismo judicial, Epp lo define como el proceso en virtud del cual una corte constitucional "crea o expande el número de derechos constitucionales". Si ello ocurre, argumenta Epp, se producen "revoluciones de derechos" (rights revolutions), que es el rótulo que parece tener en mente para la modalidad de judicialización de la política que analizamos en este trabajo.

Pasando a la segunda cuestión que nos ocupa en esta sección, esto es, identificar los factores que contribuyen a que emerjan procesos de judicialización de la política, se debe partir por constatar la extensa literatura producida en los últimos años sobre esta materia. Estos trabajos han logrado identificar una serie de elementos que se piensa facilitan el activismo judicial. En uno de ellos: "La expansión global del poder de la judicatura", de Tate y Vallinder (1995), se ofrece el siguiente resumen de las condiciones que facilitarían la aparición de un activo control judicial de la Constitución:

Los factores que contribuyen a la judicialización de la política son varios: la presencia de un régimen democrático; un sistema de separación de poderes; una cultura de derechos (...); partidos políticos débiles o coaliciones de gobierno frágiles que produzcan atochamiento en la elaboración de las políticas públicas (...); y, por último, la delegación a las cortes de autoridad para tomar decisiones en ciertas áreas de las políticas públicas(...) Dicho esto (...) la judicialización de la política puede no darse (...), porque aun bajo una constelación muy favorable de condiciones que la faciliten, el desarrollo real de la judicialización de la política requiere que los jueces tengan las actitudes personales apropiadas, y preferencias fuertes acerca del rol que desempeñan los otros poderes del Estado(... ${ }^{21}$.

De la larga y minuciosa lista de factores favorables a la judicialización de la política expuestos por Tate, es útil distinguir entre aquellos que tienen un carácter institucional y los que tienen un carácter cultural. Así, mientras un sistema democrático de gobierno y partidos políticos débiles serían factores institucionales, la presencia de jueces imbuidos de una fuerte adhesión a los derechos individuales sería un factor cultural.

Complementando la lista provista por Tate, otro especialista en el campo de los estudios judiciales comparados, Holland (1991:7), propone como elementos clave para una exitosa implementación del activismo judicial los siguientes:

(...) Podemos decir que ciertas condiciones estructurales e intelectuales parecen hacer más probable la aparición del activismo judicial. Entre las características estructurales asociadas con éste se encuentran: el federalismo; el contar con una Constitución escrita; la independencia del poder judicial; una carencia de cortes administrativas separadas; un sistema de partidos políticos competitivos; y mecanismos de acceso a las cortes constitucionales que facili- 
ten un amplio acceso ciudadano a las mismas. Ciertas tradiciones, doctrinas e ideas también pueden contribuír a la judicialización de la política: la tradición del derecho común; el concepto de gobierno limitado; una alta autoestima en los jueces, etc.

Como se advierte de la cita, Holland añade otros factores institucionales y culturales a los mencionados por Tate. Entre los elementos institucionales, debe subrayarse el rol que desempeñara la existencia de un sistema político federal, y el que exista un fácil acceso ciudadano a las cortes constitucionales para que la judicialización tenga lugar.

Respecto al rol que cumple el federalismo, Holland coincide con Martín Shapiro y Alec Stone (1994:408), quienes han argumentado que el federalismo contribuye a legitimar el activismo judicial debido a la valiosa función que desempeñan las cortes superiores de justicia en preservar y dar más vuelo a los sistemas federales, lo cual a su vez provee a las cortes de suficientes grados de apoyo político para luego obligar al Estado federal a someterse a sus decisiones. En sus propias palabras:

Puede suceder que las cortes constitucionales tengan una mayor influencia política cuando operan en sistemas políticos federales o cuasi federales. Su utilidad potencial como colaboradores del gobierno central en la difícil tarea de mantener los estados miembros bajo control, es un recurso político de tal magnitud que puede emplearse después para lograr obediencia para con sus decisiones, incluso en materias no relacionadas con el federalismo, y con respecto a decisiones que vayan en contra del gobierno central.

Como emana del análisis de Shapiro y Stone, la presencia de un régimen federal les permite a las cortes de justicia acumular una reserva de legitimidad -gracias a su acción de disciplinamiento de los Estados respecto de la Constitución federal- que después les será de gran utilidad, cuando deban declarar una ley federal como contraria a la Constitución. La contribución de este último factor a la emergencia de la judicialización de la política no es menor, como lo sugiere el contraste entre el país más judicializado del mundo, los Estados Unidos, que ha sido federal desde sus orígenes, y Nueva Zelanda, estado unitario con bajísimos niveles de judicialización de la política.

Volviendo a los factores culturales mencionados por Holland, debe destacarse el énfasis que pone en que los paises con una tradición legal del derecho común (common law), serían más propensos a la judicialización de la política que aquellos con tradiciones legales diferentes, en particular los que cuentan con un acervo legal derivado del derecho continental europeo, o derecho civil (que es, incidentalmente, el característico de América Latina y, en particular, de Chile). Asimismo, llama la atención la importancia que Holland asigna al factor "auto estima de los jueces" en la judicialización de la política. Este último elemento, a su vez, suele asociarse a lo que Mirjan Damaska (1986:17) denomina "sistemas judiciales coordinados" (típicos de los países anglosajones, en que los jueces son más asertivos y seguros de sí mismos), en contraposición con los que llama "sistemas judiciales jerárquicos" (que caracterizan a los países de tradición legal continental europea, donde los jueces se parecen a más a burócratas disciplinados y poco asertivos).

En este punto, debe destacarse otro importante factor cultural favorable a la judicialización de la política: la existencia previa de una cultura de derechos, como lo subraya Tate (1995:29-30):

Una condición mucho más relevante para la judicialización de las política parece ser la presencia de una 'cultura de derechos'(...). Esto es, el que sin perjuicio de la existencia o inexistencia de una declaración formal de derechos, exista una aceptación social del principio de 
que los individuos y las minorías tienen derechos que son obligatorios - incluso en contra de la voluntad de la mayoría (...) Cuando esta cultura existe, ésta influye en la labor de las cortes, que se transforman así en actores clave del proceso (...).

Si la judicialización de la política requiere la existencia previa de una "cultura de derechos", inmediatamente surge la pregunta acerca de cómo promover tal cultura. Dadas las dificultades que presenta introducir valores, especialistas en judicialización han abandonado esa línea de investigación volcándose en cambio al potencial provisto por elementos político/estructurales. Un ejemplo de lo anterior lo proporciona Epp (1998) quien ha enfatizado el rol de lo que denomina "estructuras de apoyo" (support structures) en la judicialización de la política. De acuerdo con este autor, estas últimas serían clave para permitir que los grupos de interés y el público en general puedan exigir una protección de sus derechos constitucionales en forma efectiva. Luego de argumentar que las explicaciones convencionales del activismo judicial (que clasifica en tres grupos, las centradas en la Constitución; las centradas en los jueces; y las centradas en la cultura), no logran dar cuenta del activismo judicial, Epp proclama que el factor clave está en la existencia de lo que él llama "estructuras de apoyo para la movilización legal". Estos recursos, juristas que abogan por los derechos, organizaciones no gubernamentales y fuentes de financiamiento, serían, según Epp (1998:2-3), factores críticos para el surgimiento de una presión 'desde abajo' que haga actuar a las cortes. En sus palabras:

(...) la atención judicial sostenida creció en primer lugar gracias a la presión desde abajo, no desde el liderazgo desde arriba. Esta presión consistió en la organización deliberada y estratégica hecha por los que abogaban por los derechos. Y el abogar por los derechos estratégicos se hizo posible debido al desarrollo de lo que denomino 'estructuras de apoyo' para la movilización legal, y que consiste en la existencia de organizaciones que abogan por los derechos; abogados especializados en ello; y fuentes de financiamiento, especialmente financiamiento pagado por el gobierno (...). La movilización legal depende también de los recursos (...) Y los recursos para el derecho a litigar dependen de una estructura de apoyo.

El problema de la teoría de Epp es que no está claro si las estructuras de apoyo que menciona son suficientes como para dar lugar a las "revoluciones de derechos" características de la judicialización de la política, si están ausentes las otras pre condiciones propuestas por la literatura a que se hizo referencia más arriba o si, por el contrario, ellas sólo pueden funcionar en conjunto con esos otros factores facilitadores.

En la misma línea que Epp, pero con otro énfasis, destaca la propuesta de los italianos Guarnieri y Pederzoli (1999:140), quienes subrayan el rol que cumple lo que denominan "la estructura general del sistema político" en la judicialización de la política. De acuerdo con estos autores, en los sistemas mayoritarios de gobierno existiría una menor chance de judicialización de la política, ya que la posibilidad de responder legislativamente de manera rápida a fallos constitucionales adversos reduciría el margen de maniobra de las cortes. Por el contrario, el poder judicial desempeñaría un rol político mucho más significativo en los sistemas políticos no mayoritarios, donde el poder se encuentra más disperso, sea como consecuencia de un federalismo robusto, la separación de poderes, o la representación proporcional22 . En todo caso, Guarnieri y Pederzoli recono-

Este factor es también mencionado por Tate (1995), p. 31, quien escribe: "Una segunda condición (que favorece el activismo judicial) es la debilidad de los partidos políticos y de las coaliciones de gobierno. Cuando el poder ejecutivo no puede gobernar mediante partidos políticos disciplinados capaces de producir mayorías legislativas sólidas, será difícil que pueda desarrollar políticas públicas capaces de resistir el embate del uso opositor de los tribunales". 
cen que esto es una generalización muy amplia, que solamente especifica una condición necesaria, pero no suficiente, para el activismo judicial, ya que incluso en regímenes no mayoritarios el poder judicial tendrá que mostrar interés en influir en la formulación de política pública para que exista judicialización de la política. Y ello depende, principalmente, de la estructura organizacional del poder judicial, en particular, de la forma como se recluta, entrena y promueve a los jueces ${ }^{23}$.

El enfoque defendido por Guarnieri y Pederzoli es similar al utilizado por Robert Kagan (1995:88118), que también enfatiza el contexto político en que funcionan las cortes como factor clave del activismo judicial. Kagan, luego de años estudiando el origen de lo que denomina "legalismo adversarial" en los Estados Unidos, argumenta que el alto grado de activismo judicial que se observa en dicho país tiene explicaciones institucionales, históricas, y político-culturales específicas, que no necesariamente pueden reproducirse en otras latitudes. De acuerdo con Kagan, los elementos que han contribuido al destacado papel que desempeñan en la formulación de políticas públicas las cortes de los Estados Unidos son los siguientes: a) un alto grado de fragmentación política del sistema político; b) un régimen federal fuerte; c) un sistema presidencial de gobierno; y d) partidos políticos relativamente débiles. En relación con los factores históricos que contribuyeron a la centralidad del poder judicial en la política norteamericana, Kagan argumenta que la aparición relativamente lenta de las burocracias gubernamentales a niveles tanto estatal como federal contribuyeron a que la población se volcara a las cortes en busca de soluciones a problemas públicos. Éstas, por su parte, pudieron responder a esta demanda gracias a las peculiares características de la organización judicial norteamericana -altamente descentralizada-, y a la forma en que se reclutan los jueces (diseño que permite el acceso a las cortes a destacados juristas y ex políticos). Finalmente, y refiriéndose a las variables culturales que influyen en el activismo judicial, Kagan menciona la extraña combinación de una cultura política que exige una amplia protección gubernamental y al mismo tiempo desconfía de la concentración del poder, lo que creó un espacio para una vigilancia constante de los actos gubernamentales por parte del poder judicial. La virtud del análisis de Kagan es que sugiere que el exportar a otras latitudes el activismo judicial a través del transplante mecánico de normas constitucionales e instituciones, no es algo fácil.

\section{LOS PELIGROS DE LA JUDICIALIZACIÓN}

Aquellos que aceptan sin más la idea de que el activismo judicial debería ser introducido desde un principio en las nuevas democracias, no están conscientes de que incluso en el caso del país con la judicialización más avanzada del mundo, los Estados Unidos, el activismo judicial de su Corte Suprema de Justicia sólo se instaló décadas después del establecimiento y consolidación de un sistema liberal-democrático, y que cuando ello ocurrió, durante la denominada "era Lochner" (1905-1937), el poder judicial estuvo a punto de ser abiertamente intervenido por el presidente Roosevelt24.

En este punto el ya clásico trabajo de Nonet y Selznick, Law and Society in Transition (1978), ofrece un valioso marco analítico para entender los peligros que involucra el apostar por la judicialización de la política en su variante de control de la constitucionalidad de las leyes en democracias no consolidadas, puesto que nos alertan acerca de la gradualidad con que las distin-

Guarnieri \& Pederzoli (1999, p. 140-141).

Para un buen análisis de la "era Lochner", véase Gillman (1993). 
tas facetas del Estado constitucional de derecho se incorporaron históricamente al acervo institucional de los Estados modernos. En su libro, los autores argumentan que el Estado de derecho comprende tres distintas dimensiones que pueden encontrarse en mutua tensión. La primera de ellas, que denominan "la dimensión represiva del derecho", es propia de los Estados autoritarios, donde el sistema jurídico "se encuentra al servicio del poder represivo del Estado"25, caracterizándose por: a) el énfasis que pone en el control social y en el orden; b) el uso de razonamientos legales ad hoc -esto es, condescendientes con el poder-; c) el uso extendido que hace de la coerción; y d) la subordinación que efectúa del derecho a los poderes políticos ${ }^{26}$. Como se advierte, la dimensión represiva corresponde a las formas más primitivas de derecho, aunque, por cierto, desempeña un papel importante incluso en aquellos lugares donde el Estado de derecho se encuentra más desarrollado.

La segunda dimensión del Estado de derecho que describen Nonet y Selznick es el "derecho autónomo", que corresponde a los elementos más fundamentales que destaca la teoría legal contemporánea, esto es: a) un énfasis en la justicia de los procedimientos, b) un razonamiento legal que valora una estricta adhesión a la autoridad del derecho; c) un uso controlado de la coerción; y d) la independencia de la judicatura respecto de los otros poderes del Estado ${ }^{27}$. Finalmente, existiría una última dimensión del Estado de derecho, que los autores denominan "dimensión sustantiva", y que representa una respuesta ante la inflexibilidad y rigidez que presenta la dimensión autónoma del derecho, especialmente cuando una aplicación estricta de la ley lleva a resultados injustos. Esta dimensión sustantiva se caracteriza por lo siguiente: a) un énfasis en la justicia sustantiva; b) un razonamiento legal menos formalista; $y, c$ ) una integración de las aspiraciones legales y políticas en la práctica de la adjudicación judicial28.

Lo interesante de esta taxonomía de las diferentes dimensiones que subyacen al Estado de derecho contemporáneo de las democracias consolidadas, es que refleja la evolución histórica del derecho como institución social, en una secuencia que va de la mano con la evolución de las sociedades actuales, que pasaron de la era tradicional a la modernidad burocrática, y luego a la crisis del formalismo legal y hacia formas más 'sustantivas' de justicia. A pesar de este decurso histórico, Nonet y Selznick subrayan que cada una de estas dimensiones persisten en mayor 0 menor medida en el Estado de derecho de las democracias consolidadas, y que cada una de estas dimensiones tiene el potencial de degenerar hacia extremos tales que incentivan la aparición de las demás ${ }^{29}$.

Nonet and Selznick (1978:14).

lbid., p. 16.

Ibid., p. 16.

Ibid., p. 16. Aunque, como lo ha puntualizado lan Shapiro (1994, p. 5), actitudes sustantivas pueden encontrarse en períodos históricos de antigua data. En sus palabras: "En occidente existe una antigua tradición de equidad que llega hasta por lo menos Aristóteles, y que autoriza a los jueces a abandonar la aplicación de reglas legales para hacer justicia en el caso particular que están analizando".

29 Esta idea ha sido subrayada por Krieger (2000, p. 31), quien, en un trabajo sobre la sociología legal de Selznick, sostiene que: " la legalidad (puede) degenerar en legalismo. Esto significa que (puede) triunfar sobre los fines (...) las reglas por sobre los propósitos, las necesidades y las consecuencias; la justicia formal sobre la justicia sustantiva; la integridad institucional sobre la apertura ante la realidad social; las proposiciones abstractas sobre los problemas concretos; y la fidelidad sobre la capacidad". 
El modelo evolutivo y algo dialéctico del Estado de derecho que ofrecen Nonet y Selznick es particularmente pertinente para el análisis de las relaciones entre control judicial de la Constitución y los procesos de consolidación democrática. En efecto, es posible describir un ejercicio activista de los poderes de control judicial en defensa de los derechos humanos -que necesariamente implican algún grado de creatividad y asertividad judicial-, como parte de la dimensión sustantiva del Estado de derecho, mientras que un ejercicio formalista y deferente del control judicial de la Constitución sería típico de la dimensión autónoma del derecho. Si esto es así, la introducción del control de la constitucionalidad de las leyes en sociedades que se encuentran recién transitando desde la fase represiva del derecho -característica de regímenes autoritarios- hacia la fase autónoma del mismo sería inconveniente, porque parece prematuro introducir prácticas propias del Estado más sofisticado de todos -la justicia sustantiva- cuando aún no se ha arrivado a la fase autónoma. Esto es precisamente lo que puede suceder si se introduce una judicialización de la política mediante el control de constitucionalidad de las leyes en democracias no consolidadas (como las de América Latina), las cuales, habiéndose recién liberado del pesado legado de sistemas legales represivos, intentan todavía consolidar un derecho con mínimos grados de autonomía respecto de la política.

Por cierto, es aún demasiado pronto para evaluar de manera conclusiva cuál ha sido el efecto del acelerado transplante del activismo judicial en las democracias emergentes, pero las primeras evidencias sugieren que éste conlleva el riesgo de destruir cualquier avance que se hubiera conseguido en lo que se refiere a dotar de un mínimo de autonomía al derecho, especialmente en lo que se refiere a la independencia del poder judicial. Si esto llegara a confirmarse, no debiera sorprender demasiado, sobre todo si se tiene a la vista el modelo evolutivo de Nonet y Selznick, que justamente enfatiza que mientras la transición desde el derecho represivo al derecho autónomo requiere el aislamiento político de las cortes, la transición desde el derecho autónomo al derecho sustantivo demanda justamente lo contrario. Dicho de otra forma, si se avanza hacia una mayor politización del derecho y de las cortes antes que los valores y hábitos del derecho autónomo estén firmemente afianzados en la sociedad, existe el riesgo de que la re politización de las cortes pueda hacer regresar al derecho a su etapa más primitiva, aquella de la ley represiva, en la cual la ley está absolutamente subordinada a la política.

La historia reciente de América Latina ofrece ejemplos de estos peligros. En efecto, la década de los noventa registra a lo menos tres casos en que los órganos encargados de controlar la Constitución fueron brutalmente intervenidos por el poder ejecutivo como respuesta a un activo uso de sus facultades de control constitucional. Ellos son Argentina, cuando el Presidente Carlos Menem aumentó el número de jueces de la Corte Suprema para asegurarse una mayoría de partidarios suyos en ella (lo que ha sido reproducido más recientemente por Néstor Kirchner, quien, de manera más sutil, ha logrado forzar la salida de gran parte de la corte heredada por Menem); Perú, cuando Alberto Fujimori cerró la Corte Constitucional, por emitir un fallo que le fue adverso; y Venezuela, cuando Hugo Chávez obligó a la presidenta de la Corte Suprema a renunciar a su cargo, asegurándose luego una mayoría en ella. Por cierto, existen unos pocos casos exitosos, como los de Colombia y Costa Rica, en que los órganos de control constitucional han exhibido niveles importantes de activismo, sin haber sido luego intervenidos por el poder político. Sin embargo, atendido lo reciente de la introducción de cortes constitucionales en dichos países ${ }^{30}$, es demasiado escaso el tiempo transcurrido para sacar cuentas alegres al respecto. 
La presencia de este riesgo explica por qué en Chile (una de las democracias emergentes en que la evolución desde el derecho represivo al derecho autónomo se encuentra más avanzada, y en que por consiguiente la independencia judicial está más institucionalizada), las cortes hayan mostrado tanta renuencia a adoptar un rol activista en su ejercicio de sus facultades de control de la constitucionalidad de las leyes, cuestión que aparentemente responde a una larga historia institucional de lucha por su autonomía, que temen se vería amenazada si abrazan irreflexivamente el camino tentador de la judicialización. Lo interesante del caso chileno es que le ha permitido evitar los retrocesos experimentados en Venezuela, Perú o Argentina, países en que las cortes intentaron hacer un uso activo de sus facultades de control para luego ser brutalmente intervenidas por los poderes políticos, perdiendo así la autonomía que habían trabajosamente adquirido.

\section{CONCLUSIÓN}

Como se describió en la primera parte de este trabajo, al poco tiempo de consumada la "tercera ola democrática" de las últimas décadas del siglo XX, se constataron graves limitaciones en las nuevas democracias que vinieron a sustituir a los autoritarismos que las precedieron. Entre otras deficiencias, la más seria es el recurrente patrón en que gobernantes elegidos democráticamente ejercen el poder de manera autoritaria, esto es, sin respetar las libertades básicas de los ciudadanos. Enfrentados a estos verdaderos "césares modernos" -que se comportan como dictadores elegidos-, estudiosos de los procesos de consolidación democrática apuestan ahora al poder judicial, específicamente en su rol de órganos de control de la constitucionalidad de las leyes como un factor fundamental en el esfuerzo por someter el poder político al derecho, y así contribuír a la consolidación de la democracia. La esperanza es que una judicatura constitucional autónoma e integrada por jueces con valores democrático-liberales haga un uso activo de los mecanismos de control de la constitucionalidad de las leyes en defensa de los derechos fundamentales de las personas. Esto, se espera, obligará a los gobiernos de las democracias emergentes a ajustar su accionar al Estado de derecho, terminando así con la escandalosa actuación de muchos gobernantes de la "tercera ola".

A pesar de lo atractivo que resulta a primera vista este planteamiento, existen, sin embargo, antecedentes que sugieren que la judicialización de la política en democracias no consolidadas, 0 es difícil de introducirse, o puede ser contraproducente. Lo primero porque en general no cuentan con los elementos estructurales y de cultura legal necesarios para el activismo judicial. Lo segundo, porque la experiencia histórica indica que en países con una débil tradición de respeto al Estado de derecho, la judicialización de la política suele acabar con la independencia de la judicatura, ya que los gobernantes -al advertir el potencial de poder político de las cortes- sucumben a la tentación de intervenir la judicatura con personas que les parezcan confiables. Aunque, por cierto, se necesita más tiempo para hacer un pronunciamiento tajante respecto del impacto de la judicialización de la política en su modalidad de control de la constitucionalidad de las leyes en los procesos de consolidación democrática, la evidencia disponible hasta el momento (así como los aportes teóricos de Nonet y Selznick) sugiere que los fracasos arriba mencionados no son algo excepcional en el contexto de regímenes con una débil tradición de respeto al Estado de derecho.

En otras palabras, la introducción prematura de procesos de judicialización de la política -al transformar a la judicatura en una arena política más- introduce incentivos irresistibles para que los gobiernos intervengan al poder judicial. Por ello, alentar la judicialización de la política en 
democracias no consolidadas, antes de que se haya institucionalizado firmemente la independencia de la judicatura, conlleva el riesgo de que en lugar de una judicialización de la política, se produzca más bien una politización de la justicia.

\section{REFERENCIAS}

Boyle, Kevin, y Adel Omar Sherif. 1997. Human Rights and Democracy: The Role of the Supreme Constitutional Court of Egypt. London and Boston: Kluwer Law International.

Chavez, Rebecca Bill. 2004. The Rule of Law in Nascent Democracies: Judicial Politics in Argentina. Stanford: Stanford University Press.

Constant, Benjamin. 1988. Political Writings. Cambridge: Cambridge University Press.

Dahl, Robert. 1957. "Decision-Making in a Democracy: The Supreme Court as a National Policy-Maker". Journal of Public Law 6: 297.

Diamond, Larry. 1999. Developing Democracy: Toward Consolidation. Baltimore and London: Johns Hopkins University Press.

Diamond, Larry y Marc Platter. 1993. The Global Resurgence of Democracy. Baltimore \& London: The Johns Hopkins University Press.

Damaska, Mirjan R. 1986. The Faces of Justice and State Authority: A Comparative Approach to the Legal Process. New Haven and London: Yale University Press.

Dworkin, Ronald. 1986. Law's Empire. Cambridge: Harvard University Press.

Dworkin, Ronald. 1978. Taking Rights Seriously. Cambridge: Harvard University Press.

Edelman, Martin.1995. "Israel". En The Global Expansion of Judicial Power, editado por N. Tate y T. Vallinder. New York: New York University Press, 403-415.

Ely, John Hart. 1980. Democracy and Distrust: A Theory of Judicial Review. Cambridge: Harvard University Press.

Epp, Charles. 1998. The Rights Revolution: Lawyers, Activists, and Supreme Courts in Comparative Perspective. Chicago and London: University of Chicago Press.

Gillman, Howard. 1993. The Constitution Besieged. The Rise and Demise of Lochner Era Police Powers Jurisprudence. Durham and London: Duke University Press.

Ginsburg, Thomas. 2003. Judicial Review in New Democracies: Constitutional Courts in Asian Cases. Cambridge: Cambridge University Press.

Glendon, Mary Ann. 1991. Rights Talk: The Impoverishment of Political Discourse. New York: Free Press.

Gloppen, Siri, et al., 2003. Democratization and the Judiciary: The Accountability Function of Courts in New Democracies. London and Portland, OR: Frank Cass Publishers.

Gray, John. 1986. Liberalism. Minneapolis: University of Minnesota Press.

Guarnieri, Carlo y Patrizia Pederzoli. 2002. The Power of Judges. A Comparative Study of Courts and Democracy. Oxford: Oxford University Press.

Guarnieri, Carlo y Patrizia Pederzoli. 1999. Los Jueces y la Política. Poder Judicial y Democracia. Madrid: Taurus.

Guarnieri, Carlo. 1992. Magistratura e Politica in Italia. Bolonia: II Mulino.

Hamilton, Alexander, James Madison y John Jay. 1945 The Federalist or The New Constitution. New York: The Heritage Press. Handelman, Howard \& Mark Tessler. 1999. Democracy and Its Limits. Notre Dame: University of Notre Dame Press.

Hilbink, Lisa. 1999. Legalism Against Democracy: The Political Role of the Judiciary in Chile, 1964-1994. Tesis doctoral presentada a la University of California, San Diego.

Holland, Kenneth.1991.Judicial Activism in Comparative Perspective. London: MacMillan.

Huntington, Samuel. 1996. "Democracy for the Long Haul". En The Global Resurgence of Democracy, editado por Larry Diamondand Marc Platter. Baltimore \& London: The Johns Hopkins University Press.

Kagan, Robert. 1995. "Adversarial Legalism and American Government". En The New Politics of Public Policy, editado por M. Landy y M. Levin. Baltimore: Johns Hopkins University. 
Karl, Terry y Philippe Schmitter.1996. "What Democracy is, and is not". En Consolidating the Third Wave Democracies: Themes and Perspectives, editado por L. Diamond and M. Platter. Baltimore y London: The Johns Hopkins University Press.

Klug, Heinz. 1997. "Bounded Alternatives: The Reception of Constitutional Paradigms and the Civilizing of Unnegotiable Conflicts in South Africa". Trabajo presentado en la Conferencia de la American Bar Foundation New Challenges for the Rule of Law: Lawyers, Internationalization, and the Social Construction of Legal Rules. University of California, Santa Barbara, November 7-9.

Koopmans, Tim. 2003. Courts and Political Institutions: A Comparative View. Cambridge: Cambridge University Press.

Krieger, Martin. 2000. "Philip Selznick and the Rule of Law". Trabajo presentado a la Conferencia en Homage to Philip Selznick. Center for the Study of Law and Society, University of California at Berkeley. April 14.

Linz, Juan y Alfred Stepan. 1996. “Toward Consolidated Democracies”. En Consolidating the Third Wave Democracies: Themes and Perspectives, editado por L. Diamond y M. Platter. Baltimore and London: The Johns Hopkins University Press.

Nino, Carlos Santiago. 1996. The Constitution of Deliberative Democracy. New Haven: Yale University Press.

Nonet, Philippe y Philip Selznick. 1978. Law and Society in Transition: Toward Responsive Law. New York: Harper Torch Books.

O'Donnell, Guillermo, Juan Méndez y Paulo Pinheiro.1999. The (Un) Rule of Law and the Underprivileged in Latin America. Notre Dame: University of Notre Dame Press.

O'Donnell, Guillermo. 1998. Counterpoints. Selected Essays on Authoritarianism and Democratization. Notre Dame: University of Notre Dame Press.

Ranney, Austin. 1996. Courts and the Political Process: Jack W. Peltason's Contributions to Political Science. Berkeley: Institute for Governmental Studies.

Rogoswky, Ronald. "Democracy, Capital, Skill, and Country Size". En The Origins of Liberty, editado por P. Drake y M. McCubbins. Princeton: Princeton University Press.

Schmitter, Philippe. 1993. "Dangers and Dilemmas of Democracy". En The Global Resurgence of Democracy, editado por L. Diamond y M. Platter. Baltimore \& London: The Johns Hopkins University Press, 1993.

Schumpeter, Jospeh. 1942. Capitalism, Socialism, and Democracy. New York: Harper and Row.

Schwartz, Herman. 2000. The Struggle for Constitutional Justice in Post-Communist Europe (Constitutionalism in Eastern Europe). Chicago: University of Chicago Press;

Shapiro, lan. 1994. The Rule of Law: NOMOS XXXVI. New York: New York University Press.

Shapiro, Martin y Alec Stone. 1994. "The New Constitutional Politics of Europe". Comparative Political Studies 26 (4) *.

Shapiro, Martin. 1964. Law and Politics in the Supreme Court: Studies in Political Jurisprudence. Glencoe, IL: Illinois Free Press.

Shapiro, Martin. 1962. The Supreme Court and Public Policy. Glenview, IL: Scott, Foresman.

Seitzer, Jeffrey. 1999. "Experimental Constitutionalism: A Comparative Analysis of the Institutional Bases of Rights Enforcement in Post-Communist Hungary". En Constitutional Dialogues in Comparative Perspective, editado por S. Kenney, W. Reisinger y J. Reitz. London: Macmillan and New York: St. Martin's Press.

Smith, Eivind (ed.). 2003. The Constitution as an Instrument of Change. Stockholm: SNS Forlag.

Solyom, Laszlo, and Georg Brunner, eds. 2000. Constitutional Judiciary in a New Democracy : The Hungarian Constitutional Court. UMP.

Stone, Alec. 1992. The Birth of Judicial Politics in France. Oxford and New York: Oxford University Press.

Stotzky, Irwin (ed.). 1993. Transitions to Democracy in Latin America: The Role of the Judiciary. Boulder Co:Westview Press. Sunstein, Cass. 1988. "Constitutions and Democracy: An Epilogue". En Constitutionalism and Democracy, editado por J.

Elster y R. Slagstad. Cambridge: Cambridge University Press.

Tate, Neal y Torbjorn Vallinder. 1995. The Global Expansion of Judicial Power. New York: New York University Press.

Tate, Neal. 1995. "Why the Expansion of Judicial Power?". En The Global Expansion of Judicial Power, editado por N. Tate y T.

Vallinder. New York: New York University Press, 27-37.

Tocqueville, Alexis. 1990. Democracy in America. New York: Vintage Classics.

Tushnet, Mark. 1999. Taking the Constitution Away From the Courts. Princeton: Princeton University Press.

Volcansek, Mary. 2000. Constitutional Politics in Italy. New York: St. Martin's. 
Volcansek, Mary. 1994. "Political Power and Judicial Review in Italy". En Comparative Political Studies 26 (4): $492-509$.

Weiler, Joseph. 1994. "A Quiet Revolution. The European Court of Justice and Its Interlocutors". Comparative Political Studies 26 (4): 510-534.

Zakaria, Fareed. 1997. “The Rise of Illiberal Democracy”. Foreign Affairs 76 (6) : 22-43.

Javier Couso es Licenciado en Derecho de la Universidad Católica de Chile y Ph. D. en Jurisprudence and Social Policy por la Universidad de California, Berkeley. Actualmente es profesor de Derecho y Ciencias Políticas en la Universidad Diego Portales, donde también se desempeña como Director del Centro de Investigaciones Jurídicas y como miembro del Consejo del Instituto de Ciencias Sociales. Publicaciones recientes incluyen: "The Politics of Judicial Review in Chile in the Era of Democratic Transition, 1990-2002", en Democratization, (Winter 2003, Volumen 10 Number 4, pp: 70-91); y "La producción del derecho económico internacional y la necesidad de una democracia cosmopolita", en El derecho como objeto e instrumento de transformación (Buenos Aires: SELA-Ediciones del Puerto, 2003, pp: 113-133).

(E-Mail: javier.couso@udp.cl) 